\title{
O ENCONTRO DOS ATORES NO CENÁRIO DAS UNIDADES DE HEMODIÁLISE
}

[The actors' meet the scenery of the units of hemodialysis]

\author{
Daisy Doris Pasqual* \\ Ymiracy Nascimento de S. Polak**
}

\begin{abstract}
RESUMO: Este estudo teve como objetivo refletir sobre as situações de encontro, nas unidades de hemodiálise que propiciam a interação enfermeirocliente, permitindo o crescimento mútuo e solidificando as ações de cuidado. O cenário mecanicista e rotinizado parece não propiciar a formação deste encontro tão importante para a instauração do cuidado.
\end{abstract}

PALAVRAS-CHAVE: Equipe de Enfermagem; Cuidadores; Relação Enfermeiro-Paciente; Hemodiálise.

\section{INTRODUÇÃO}

Percebemos que, em pouco mais de meio século, deixamos a postura de completa imobilidade que nos impedia de modificar a história natural da síndrome urêmica à compreensão de grande parte dos fenômenos que ocorrem no seu desenvolvimento, ao controle da maioria das suas alterações metabólicas e hidroeletrolíticas (RIELLA, 1996). Graças aos avanços tecnológicos e terapêuticos, tem se observado um aumento na qualidade de vida do cliente portador de Insuficiência Renal Crônica (IRC) embora continue sendo um acometimento potencialmente grave que repercute em todos os órgãos e sistemas do organismo (CIANCIARULLO; FUGULIN; ANDREONI, 1998). Registra-se maior longevidade

\footnotetext{
*Enfermeira, Mestranda em Enfermagem pela Universidade Federal do Paraná, Membro do Grupo de Estudos Multiprofissional em Saúde do Adulto - GEMSA - do Departamento de Enfermagem da UFPR. ${ }^{* *}$ Enfermeira, Doutora em Filosofia da Enfermagem pela Universidade Federal de Santa Catarina, Pós-Doutora em Educação a Distância e Tecnologias da Educação, professora participante do Programa de Pósgraduação em Enfermagem, membro do Grupo de Estudos Multiprofissional em Saúde do Adulto - GEMSA - do Departamento de Enfermagem da UFPR.
}

deste grupo bem como melhora, embora incipiente, nas condutas terapêuticas que tendem a equilibrar modelos distintos de cuidar, porém complementares, tais como o modelo biomédico, vindo ao encontro do modelo voltado para as condições socioculturais e econômicas do cliente.

O contraditório presente nesta situação é transformado nos momentos de encontro, quando o médico, ao questionar e orientar condutas que destoam dos aceitos pela cultura vigente, geram novas questões e definições de outras estratégias terapêuticas, nascendo deste inaparente confronto outras questões que levarão a novas posturas e, assim, neste dinamismo constante, a equipe e o cliente vão ajustando condutas e determinando novas formas de enfrentamento tão importantes ao renal crônico.

O portador de Insuficiência Renal Crônica é uma fonte inesgotável de sentimentos, pois a doença crônica não é transitória, ela veio para ficar, impondo ao indivíduo várias mudanças no seu estilo de vida e de sua família. Essas mudanças são drásticas e têm que ser imediatas, não oferecendo muitas escolhas, provocando uma gama de sentimentos controversos, visto que uma hora expressa uma vontade imensa de viver, de persistir, outra de abandonar tudo e se entregar para a morte, de parar com tanto sofrimento. Tem ainda que conviver com o estigma que a sociedade cria em torno do doente crônico, visto que passa a ser rotulado "não como portador de doença, mas como sendo a própria doença" (CIANCIARULLO,1998). Dentro deste turbilhão de sentimentos há uma equipe de enfermagem pouco preparada para lidar com esses conflitos, pois todo o seu aprendizado foi sempre voltado para ajudar na cura das doenças. Não foi transmitido a essa equipe o conhecimento das ciências humanas para ajudar este cliente a 
desenvolver mecanismos que facilitem a aceitação da doença e suas conseqüências. Então como ajudá-lo a superar o impacto causado por este diagnóstico? Nesse cenário surge a hemodiálise, criando ou minimizando conflitos, mas também como resposta para o prolongamento da vida.

O cliente renal crônico vive uma verdadeira via crucis. Ele é submetido, várias vezes por semana, a sessões de hemodiálise e diálise peritoneal, durante as quais fica parado, olhando para um horizonte longínquo ou desconhecido, até mesmo perguntando: Será que isto vai acabar? Será que terá fim esse sofrimento? Paralelo a este monólogo registra-se o entra e sai da enfermagem, a pressa em instalar banhos, puncionar fístulas, monitorar sinais vitais, fazer registros e cumprir as funções instrumentais que lhe são conferidas.

Diante desses dois quadros, de um lado só silêncio, melancolia e até distanciamento do cliente, e do outro o fazer, o cumprir a escala de trabalho, surgem vários questionamentos, tais como: Como o cuidador e o ser cuidado se percebem na relação de encontro durante a hemodiálise?

Acredito que para nos aproximarmos e nos encontrarmos do ser cuidado, é preciso, no primeiro momento, conhecermos a nós mesmos; é preciso ter consciência do próprio corpo, ouvir suas mensagens, saber se está triste ou alegre, tenso ou relaxado; precisamos "usar o corpo para ver, ouvir, cheirar, tocar... ser capaz de perceber o mundo por meio do próprio contato com ele (SILVA,1998,p.134), pois só mediante o nosso próprio conhecimento é que podemos nos mostrar, dizer que estamos presentes, não como máquinas, desempenhando como autômatos nossas funções, mas como agentes carregados de valores, crenças e conhecimentos, conscientes do nosso papel na enfermagem que, segundo $\operatorname{Beck}(1997$, p.53), é "independente da cura, manter o cliente assistido, com bem-estar e com possibilidades de alcançar níveis satisfatórios de qualidade de vida".

A hemodiálise é uma terapia que não cura a insuficiência renal, mas ajuda a preservar a vida até que surja um tratamento melhor ou até que as condições clínicas ou psicológicas do cliente declinem para a sua finitude, algo concreto na existência humana, na qual só nos resta, enquanto equipe, ajudar o processo de transição vida-morte, o que é bastante difícil em virtude da nossa formação, porquanto os currículos da área da saúde não contemplam adequadamente as condições de cronicidade, não preparam o profissional para viver situações limitantes; tampouco auxiliar o outro, mostrando-Ihe que pode ter uma vida normal, a partir do momento em que aceite sua condição de cronicidade e aprenda a conviver dentro das limitações impostas pela doença.

\section{O CENÁRIO}

Atuando há mais de vinte anos, neste cenário, diretamente na hemodiálise, posso afirmar que, perante a evolução tecnológica, é possível obter-se melhora na qualidade de vida do renal crônico, mas pouco se tem escrito ou se tem feito para se conhecer ou melhor trabalhar a questão em relação aos sentimentos inerentes a essa clientela, quer em relação aos clientes e familiares, quer em relação à equipe de enfermagem e às ações desenvolvidas neste cenário.

A hemodiálise pode proporcionar reabilitação e expectativa de vida razoáveis; entretanto não cura nem reverte a doença renal e não é capaz de compensar as perdas endócrinas e metabólicas do rim. Os objetivos da hemodiálise são extrair substâncias nitrogenadas tóxicas do sangue e remover o excesso de água (SMELTZER; BARE, 1994). É um processo extracorpóreo, no qual o sangue é forçado a passar por um filtro composto de uma membrana semipermeável, banhada pelo líquido de diálise que, através dos processos de difusão e osmose, permite a remoção das toxinas urêmicas e o excesso de água.

A contínua automatização dos equipamentos tem permitido o controle preciso da ultrafiltração (RIELLA, 1996) e a diminuição das intercorrências habitualmente observadas, como: hipotensão, cãibras, náuseas, vômitos e cefaléias severas. Porém, as complicações ósseas, anemia, desnutrição e hipertensão ainda estão presentes no dia-dia das unidades e na vida dos clientes.

Observa-se que, nesse período, houve acentuada massificação do tratamento; que produziu uma equipe de enfermagem que não se reconhece mais, que transformou em sacrifício a arte e o fazer enfermagem, no qual o cliente passou a ser mais um, imposto por uma demanda cada vez maior de clientes. Essa equipe foi obrigada a deixar 
de lado a essência da sua profissão, que é o cuidar, pois o "cuidado é relação, expressão, envolve empatia, autenticidade, aceitação, um dispor-se, um estar sempre junto com o ser cuidado" (LACERDA,1999, p.10); o crescimento da mecanização, não só dos equipamentos, mas também dos cuidados de enfermagem. Quando o cliente passa a fazer parte dos equipamentos de hemodiálise, este passa a ser uma extensão da engrenagem da máquina de diálise. A tecnologia fez com que corpos que cuidam de corpos se transformassem em corpos robotizados, imunes e dissociados de sentimentos, corpos que transformam o cuidar em tarefa, em ação mecânica que restaura e recupera outros corpos também robotizados.

Pouco a pouco, o cliente foi sendo inserido na máquina de diálise, como engrenagem que começa a funcionar quando, ligamos o botão $O N$ da máquina e que, no final do tratamento apertamos o OFF, desligamos o equipamento e dispensamos o cliente e pronto, cumprimos com nossa obrigação. As palavras cuidar/cuidador foram abolidas das salas de hemodiálise, como parece ter sido também esquecido o ser humano que precisa desta máquina para sobreviver.

Não existem mais sentimentos, pois dominamos com grande perícia as máquinas e se uma engrenagem falhar, amanhã em seu lugar vai haver outro e assim, por diante, sem atentarmos que, por nossas mãos, estão passando vidas e que estas estão carregadas de medo, insegurança, desconfiança, raiva e esperança, sentimentos que estão muito além da frieza das salas de hemodiálise e do entendimento da equipe de enfermagem.

O cliente não é mais assistido/cuidado em hemodiálise; ele é ligado à máquina, ele é desligado da máquina. WALDOW (2001, p.64) ressalta:

"o mundo da tecnologia avançada agora pode substituir o corpo e o toque. O afago, o aperto de mão, oferecendo apoio e suporte, ou mesmo o olhar carinhoso e amigo parece não ser mais necessário. A máquina passa a realizar o cuidado e a cuidadora a ocupar-se, absorvendo-se e concentrando-se no manuseio da mesma, por vezes esquecendo o ser humano a ela conectado."

Para minimizar este comportamento robotizado é preciso estabelecer uma relação de trocas, em que a enfermagem possa ajustar suas ações nas reais necessidades do cliente, ser individual, de especificidade única, exercendo cuidados mais humanizados, "sermos vistos como seres singulares e humanos que assistem a outros seres singulares e humanos, sem negar nossas necessidades de cuidados e sem deixar de cuidar de nós mesmos" (CARRARO, 2001, p.155).

\section{O ENCONTRO}

O dia-a-dia das salas de hemodiálise é vivido sob o clima de horários, normas e técnicas pouco flexíveis, que transformam o saber fazer da enfermagem em mero fazer por fazer. Ao adentrarem para as salas de tratamento, penso perceber que os profissionais se despem de sua condição humana para se tornarem homens máquinas cuidando de clientes, que são percebidos como máquinas também. Esse cotidiano que deveria transmitir ao cliente renal segurança, conforto, proximidade e receptividade transformou-se em ambiente hostil, frio, desprovido de um mínimo de calor humano.

Destaco que a tecnologia, pela tecnologia sem o mínimo de empatia, subjetividade e intencionalidade se constitui no grande inimigo, pois tal cenário vive com o paradoxo apológico: tecnologia versus certo descaso que o cuidador tem pelo receptor do cuidado, dado este histórico na enfermagem, como podemos perceber na fala de POLAK (1997, p.93):

\begin{abstract}
"a atenção voltada para o órgão doente e para a patologia contribui com a visão do hospital como oficina na qual o corpo tem suas partes afinadas, ajustadas, removidas ou substituídas. Essa postura possibilita a percepção da equipe de saúde como composta de mecânicos responsáveis pela reposição, pela revisão e manutenção de toda a engrenagem."
\end{abstract}

Este cenário mecanicista e rotinizado impede que os profissionais se mostrem como seres humanos que são; eles não se envolvem, não se identificam com o cliente, não criam laços com este indivíduo que vai ficar sob seus cuidados por três a quatro horas, três vezes por semana. Cuidar é ação intencional (POLAK, 1996), no qual o cuidador tem a intenção de prestar o cuidado 
necessitado pelo cliente, para que a intenção seja bem sucedida; o cuidador precisa estabelecer laços com o ser cuidado; esses laços só serão estabelecidos no momento em que o cuidador se aproximar do seu cliente e for ao encontro dele; se o encontro não acontecer, não haverá cuidado, haverá apenas a execução de procedimentos técnicos; "daí a importância de que eles se conheçam, estabeleçam relações, criem e compartilhem um clima afetivo, ético e humano, necessário ao desenvolvimento das ações de enfermagem" (POLAK, 1996, p.97).

As situações de encontro são inexistentes dentro da sala de hemodiálise, pois o encontro é algo especial; é único para cada situação; é único para cada ser envolvido e não se pode chamar de encontro o simples estar com o cliente na sala de hemodiálise. O encontro se concretiza, quando o eu se deixa conhecer pelo outro, da mesma forma que o outro também permite que eu o conheça. Mesmo a convivência praticamente diária estabelecida com o cliente renal crônico não se transforma em encontro, pois não há sentimentos, não há trocas. A preocupação da equipe é com o horário, imposto pela sociedade e pelo equipamento de ponta que vai tratar a doença do cliente.

Não há consciência por parte da equipe de que as ações de cuidado, vividas por ambos, é um encontro de vidas, em que a especificidade de cada um possibilita o descobrir e o redescobrir de realidades únicas, provocando a construção e reconstrução de outras realidades que venham a garantir uma ação de cuidado também única para aquele sujeito, bem como propicie a construção de novos conhecimentos para o sujeito cuidador.

Esse conhecimento só pode emergir, quando o cuidador se encontra face a face com o ser cuidado durante as ações de enfermagem; no face a face, se estabelece o encontro, pois o cuidador convida o sujeito a participar da sua rearmonização; esta parceria afasta a fragmentação do indivíduo, reconhecendo-o como um ser de relações.

O encontro pressupõe troca, crescimento mútuo, comunhão de sentimentos; não é ato egoísta, ele é despretensioso; é aceitar aquilo que o outro tem para oferecer naquele momento. Percebo que a equipe de enfermagem não está preparada para este encontro, que não sabe fazer essa troca, pois não aprendeu a fazer essa comunhão de sentimentos; ela aprendeu a lidar com os equipamentos, com as rotinas e as normas. BOFF (2002, p. 99) diz que "há algo no ser humano que não se encontra nas máquinas, surgido há milhões de anos... o sentimento, a capacidade de emocionar-se, de envolver-se, de afetar e ser afetado". A equipe de enfermagem não se emociona mais, não se sensibiliza mais com a dor e o sofrimento que a doença renal crônica impõe ao seu cliente.

Enquanto profissionais de enfermagem não podemos esquecer que somos dotados de sentimentos e de sensibilidade, que temos de saber ouvir e perceber o outro, aliar habilidade e destreza manual no desenvolvimento das práticas tecnológicas, sempre direcionados ao cliente como um todo, como ser global que se expressa e que se comunica com outros seres. Para prestar cuidado ao corpo enfermo, é imperativo que se construa uma relação entre o corpo cuidador e o corpo cuidado, relação que deve ser alicerçada na confiança mútua e na verdade, relação de compromisso entre corpos cuidadores e corpos cuidados, pois "cuidar de alguém implica entendê-lo, adentrar em seu mundo, perceber-se fazendo parte deste mundo"( POLAK, 1997)

Precisamos entender que este corpo está deixando para trás seus sonhos, seus objetivos de vida; seu mundo foi desmoronado pela notícia da insuficiência renal crônica; para isto faz - se necessário que estejamos preparados para lidar com esta carga de sentimentos contraditórios que este corpo está carregando para dentro da sala de hemodiálise. Só poderemos lidar com esses fenômenos, se estivermos de bem com a vida e com o nosso corpo; que o centro da nossa preocupação seja o cliente. O cuidado só se transforma em ação concreta, quando existir a união entre o ser cuidador e o ser cuidado.

No cenário tecnológico das salas de hemodiálise, cujos equipamentos são instrumentos de cuidado, é mister a ação humanizada nas práticas do cuidar, uma vez que o dia-a-dia tende a robotizar os corpos cuidadores, criando "uma distância do cliente por parte da equipe, que cumpre a escala de trabalho, que está pouco disponível, falta diálogo; o corpo é instrumento de trabalho; há pouca orientação do cliente e a percepção deste é 
situacional e os cuidados conduzidos por rotineiros e normas rígidas" (Polak,1997, p.44). A rapidez com que as novas tecnologias chegam ao mercado de trabalho exigem que o profissional de enfermagem esteja cada vez mais qualificado para desenvolver suas funções. Sua qualificação não deveria estar atrelada somente ao desenvolvimento prático; ela deveria estar também embasada no desenvolvimento das ciências humanas "que o habilitam a agir com propriedade e não como simples ato caridoso ao exercer Enfermagem" (Rubin, 1997, p.27).

"O cuidado representa a união entre dois seres humanos, construída a partir de suas experiências de vida, oportunidade em que acontecem as trocas, aprendizado e desenvolvimento mútuos, exigindo que ambos revelem o seu ser, e resgatem a humanidade existente em cada um" (Wolff, Gonçalves, Yede, 1998, p.32). É nas experiências de vida do corpo cuidador e do corpo cuidado que devemos resgatar o humano de nossas atividades; é na aproximação do outro que estaremos deixando de lado as atitudes robóticas adquiridas nos últimos anos. É no resgate do comprometimento com o ser cuidado que estaremos olhando esse ser como um todo, um ser que é biológico, que é psicológico, é ser social e sobretudo é um ser existencial, pois a partir do momento em que esse ser se transforma em cliente renal crônico, já estamos fazendo parte do seu mundo, da sua vida e ele já é parte da nossa. O nosso ambiente de trabalho, de cuidado passa a fazer parte da vida dele também; esse ambiente passa a ser prolongamento da sua casa, e é em nossa casa que nos sentimos bem, aconchegados e protegidos de tudo e de todos.

\section{CONSIDERAÇÕES FINAIS}

As ações repetitivas no cotidiano das unidades de hemodiálise, aliadas à ênfase da tecnologia de ponta, distanciaram os cuidadores da essência da enfermagem, que é o cuidado e para que o cuidado se estabeleça, o cuidador tem que estar próximo do outro, tem que estar com ele e entrar no seu mundo e nos seus sentimentos; ir ao encontro do outro.

O cuidado está sempre relacionado ao outro, deve traduzir conhecimento e sensibilidade; deve, acima de tudo fazer com que o cuidador e o ser cuidado transformem os momentos de insegurança e tristeza em momentos de encontro e crescimento.

O encontro entre equipe de enfermagem e cliente renal crônico só se dará a partir do instante em que a equipe começar a desvelar seus próprios sentimentos, entendê-los, aceitar suas limitações e suas fraquezas para, no segundo momento, desvelar os sentimentos que envolvem o renal crônico, reconhecendo e aceitando também suas limitações. Assim, faz-se necessário resgatar urgentemente, dentro do mundo tecnológico da hemodiálise, a essência da enfermagem, isto é, o cuidar de seres humanos por cuidadores mais humanizados.

ABSTRACT: This study had in view a simple reflection on situations in the units of hemodialysis that propitiate the interaction nurse-patient, allowing the mutual growth and humanizing the actions of care. Mechanical scenery and routine do not seem suitable for the formation of such in important renewal to begin and up-to-dating of the care.

KEY WORDS: Nursing Team; Caregivers; NursePatient Relation; Hemodalysis.

\section{REFERÊNCIAS}

1. BECK, C.L.C. A enfermagem fazendo a diferença na vida dos pacientes, através da enfermagem. In: WESTPHALEN, M.E.A .; CARRARO, T. E. Metodologias para a assistência de enfermagem: teorizações, modelos e subsídios para a prática. Goiâna: A B - Editora, 2001. p. 147 157.

2. BOFF, L. Saber cuidar: ética do humano compaixão pela terra. 8.ed. Petrópolis: Vozes, 2002.

3. CIANCIARULLO, T. I.; FUGULIN, F. M. T.; ANDREONI, S. A hemodiálise em questão: opção pela qualidade assistencial. São Paulo: Ícone, 1998.

4. LACERDA, M. R.; COSTENARO,R.G.S. O cuidado como manifestação do ser e fazer da enfermagem. Vidya, n.32, p.8. 1999.

\section{POLAK, Y. N. S. A corporeidade como resgate do humano na enfermagem. Pelotas: Editora}


Universitária, 1997.

6. A corporeidade como resgate do humano na enfermagem. Florianópolis, 1996. Tese (Doutorado em Filosofia da Enfermagem) Universidade Federal de Santa Catarina.

7. RIELLA, M. C. Princípios de nefrologia e distúrbios hidroeletrolíticos. 3. ed. Rio de Janeiro: Guanabara Koogan, 1996.

8. RUBIN, M. A. S. Refletindo e sonhando enfermagem. Cogitare Enfermagem Curitiba, v.2, n.2, p.26-29,1997.

9. SILVA, M. J. P. Reflexões sobre a relação interpessoal no cuidar: o fator corpo entre a enfermeira e o paciente. In: MEYER, D. E.; WALDOW,V.R.; LOPES,M.J.M. Marcas da diversidade: saberes e fazeres da enfermagem contemporânea. Porto Alegre: Artes Médicas. 1997

10. SMELTZER, S. C.; BARE, B. G. Brunner \& Suddarth tratado de enfermagem médico- cirurgica. 7.ed. Rio de Janeiro: Guanabara Koogan, 1994.

11. TRENTINI, M.; SILVA, D. G. V. Condição crônica de saúde e o processo de ser saudável. Texto e Contexto, Florianópolis, v.1, n. 2, p. 76-88, jul./dez. 1992.

12. WALDOW, V. R. Cuidado Humano: o resgate necessário. 3.ed. Porto Alegre: Sagra Luzzatto, 2001.

13. WOLFF, L.D.G. GONÇALVES,L.S. YEDE,S.B. Cuidar/cuidado:elementos e dimensões na perspectiva de pessoas internadas em hospital de ensino. Cogitare Enfermagem Curitiba, v.3 n.1, p.32-39,1998.
ENDERECODASAUTORAS:

Rua: Bernardo Staviski, 357 Campina do Siqueira.CEP 80730-240 Curitiba - Paraná Tel.:335-7206/ 9973-3194 E-Mail: dpasqual@rla01.pucpr.br 